\title{
'Him makeum walk straight': using simulation to explore Australian Aboriginal skin groups
}

\author{
A.H. Dekker \\ Dekker Consulting, P.O. Box 3925, Manuka, ACT, 2603, Australia \\ Email: dekker@acm.org
}

\begin{abstract}
In Dekker (2019), while arguing for the use of agent-based computer simulation as a tool for understanding the function of anthropological phenomena, we explored the system of 8 "skin groups" or "subsections" used across central northern Australia (Figure 1). We noted in passing the well-known fact that this system has the structure of the dihedral group $\mathrm{D}_{4}$. In this paper, we address the question: why $\mathrm{D}_{4}$ ? We report further analyses and NetLogo-based simulations comparing this system against alternative structures derived from group theory, and show that this system based on $\mathrm{D}_{4}$ was indeed better than the alternatives: genetically, in story transmission, and with regard to formal properties. Table 1 summarises our findings.
\end{abstract}

Table 1. Comparing the "subsection" system of 8 Aboriginal skin groups against four alternatives

\begin{tabular}{|c|c|c|c|c|c|c|}
\hline \multicolumn{2}{|c|}{ System } & $\begin{array}{l}\text { Spousal } \\
\text { symmetry }\end{array}$ & $\begin{array}{c}\text { Paternal } \\
\text { 2-cycles }\end{array}$ & $\begin{array}{c}\text { Distinct } \\
\text { grandparents }\end{array}$ & $\begin{array}{l}\text { Genetic } \\
\text { benefits }\end{array}$ & $\begin{array}{c}\text { Story } \\
\text { preservation }\end{array}$ \\
\hline \multicolumn{2}{|c|}{$\mathrm{D}_{4}$ (system actually used) } & $\nu$ & $\nu$ & $\nu$ & $\checkmark v$ & $\nu$ \\
\hline \multirow{4}{*}{ 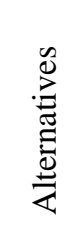 } & $\mathrm{Z}_{8}$ & - & $\nu$ & - & $\checkmark v V$ & - \\
\hline & $\mathrm{Z}_{8}(\mathrm{~b})$ & - & - & - & $\nu$ & - \\
\hline & $\mathrm{Z}_{2} \times \mathrm{Z}_{4}$ & - & $\checkmark$ & - & $\nu$ & - \\
\hline & $\mathrm{Q}_{8}$ & - & - & - & $\nu$ & - \\
\hline
\end{tabular}

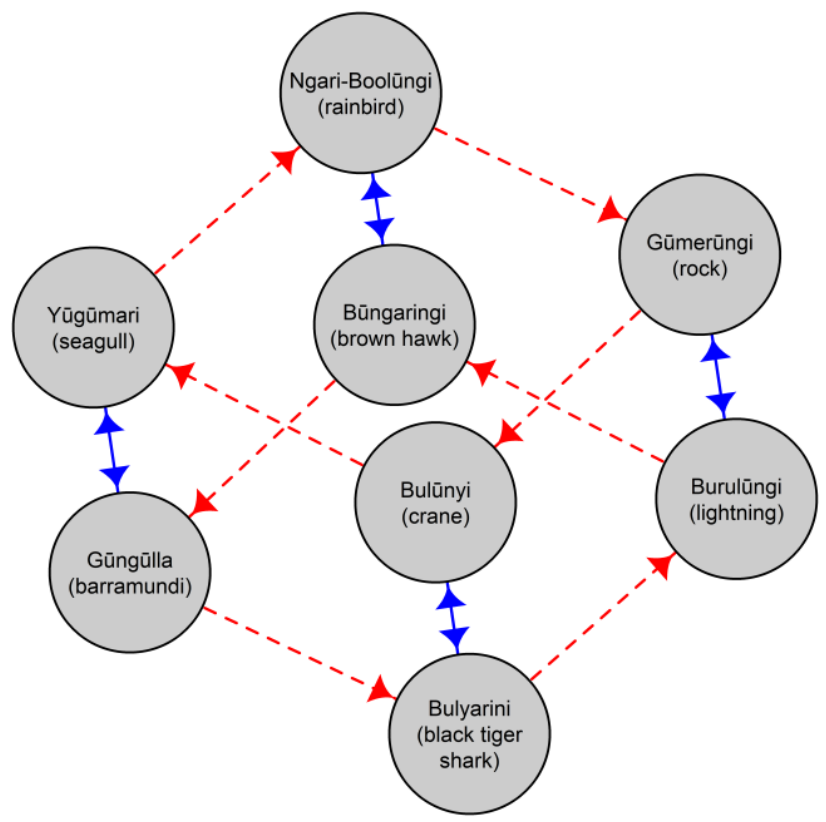

Figure 1. The 8 skin groups ("subsections") of the Lardil people. Single-headed red arrows run from mother to child $(\mu)$, and double-headed blue arrows run between father and child $(\phi)$. Note that $\mu^{4}=\phi^{2}=i$ (where $i$ is the identity).

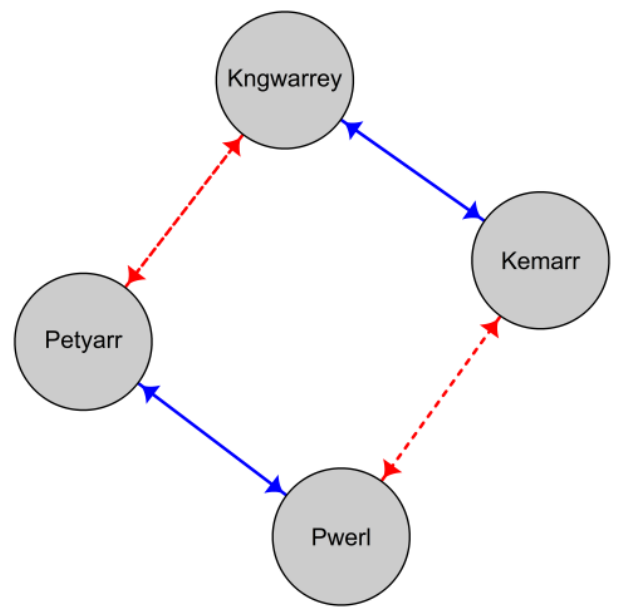

Figure 2. The 4 skin groups ("sections") of the Alyawarr people. Dashed red arrows run between mother to child $(\mu)$, and solid blue arrows run between father and child $(\phi)$. Valid marriages are vertical or horizontal, i.e. Kngwarrey with Pwerl and Petyarr with Kemarr. Note that $\mu^{2}=\phi^{2}=i$.

Keywords: Agent-based modelling, NetLogo, Anthropology, Skin groups, Aboriginal culture 


\section{INTRODUCTION}

In Dekker (2019), we argued for the use of agent-based computer simulation as a tool to assist with understanding the function of anthropological and social phenomena. We did so using two case studies, one of which involved the "skin group" system used by the Lardil people of Mornington Island, Queensland (McKnight, 1999). Essentially the same system of 8 skin groups is used across central northern Australia, but the Lardil version was highlighted because the documentation of this system by Binnion (1987) has been endorsed by the Lardil people themselves. Figure 1 shows the 8 Lardil skin groups. The dashed red arrows $(\mu)$ map the skin groups of mothers to the skin groups of their children, while the solid blue arrows $(\phi)$ map the skin groups of fathers to the skin groups of their children.

In Dekker (2019), we showed that this skin group system, generally known to anthropologists as the "subsection" system, has important genetic benefits. In particular, it reduces the death rate due to lethal recessive genes, and it does so by encouraging exogamy, as previously suggested by White and Denham (2007) and McConvell (2018a). Where particular sets of skin groups are custodians of sacred stories, it also facilitates the survival of stories which encode knowledge vital to the long-term survival of the tribe.

We noted in passing in Dekker (2019) the well-known fact that this 8-skin or "subsection" system has the structure mathematicians call the dihedral group $\mathrm{D}_{4}$. This, of course, raised the question: why $\mathrm{D}_{4}$ ? Why not some other mathematical structure? Is this system based on $\mathrm{D}_{4}$ better than the alternatives in some way? In this paper we report further simulation experiments and analyses which shed light on these questions.

\section{HISTORICAL BACKGROUND}

The 8-skin or "subsection" system in Figure 1 is found only in Australia (McConvell, 2018b), and is used, with various names, across central northern Australia (Figure 3). Some tribes assign different names to men or women within a skin group, or different names to adults and children, so that there may be more than 8 names. As well as restricting valid marriages, the system is intimately involved with many aspects of Aboriginal culture.

Analysis of the different names assigned to skin groups in different languages indicates that the 8 -skin or "subsection" system had a single point of origin, somewhere in the general vicinity of Katherine in the Northern Territory, between about 1,000 and 2,000 years ago (McConvell, 2018b).

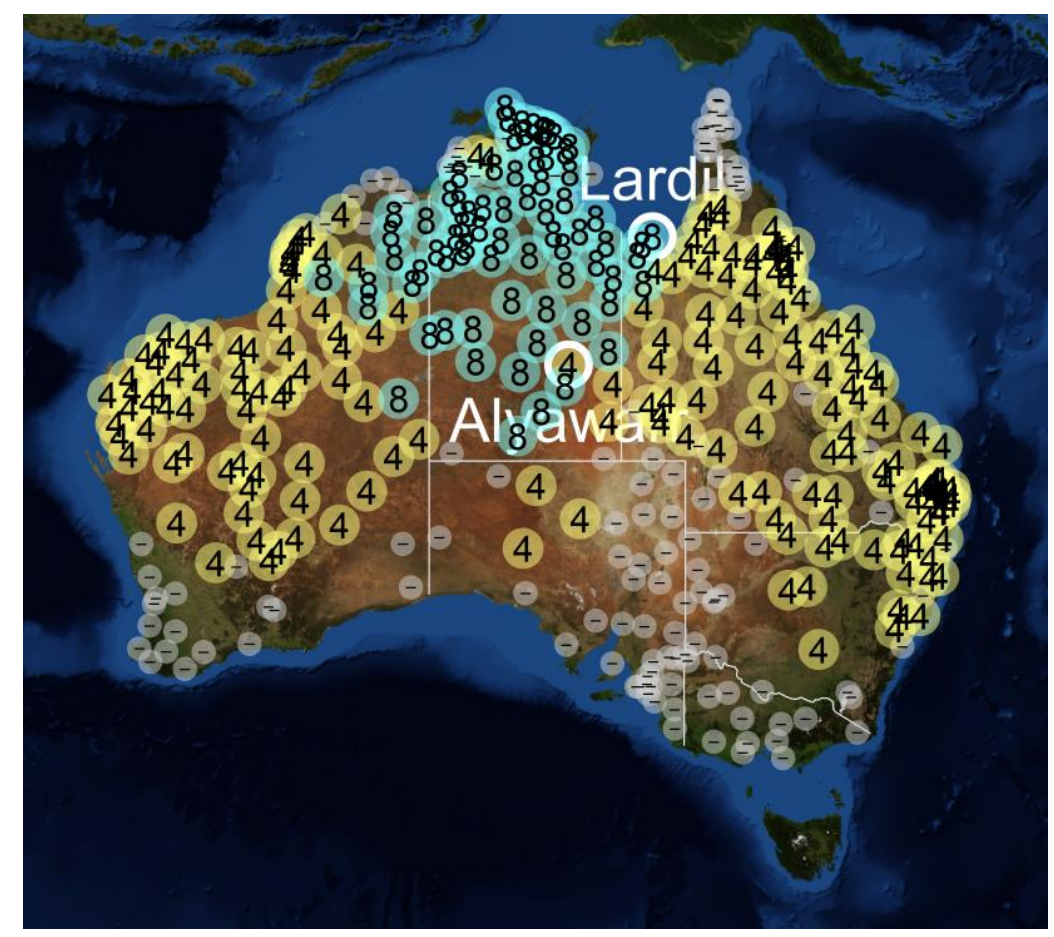

Figure 3. Skin group systems across Australia, using data from the AustKin website (AustKin, 2021; Dousset, 2018). The symbol "8" indicates 8-skin or "subsection" systems, and the symbol "4" indicates 4skin or "section" systems. Dashes indicate other systems. The two systems in Figure 1 and Figure 2 are highlighted in white. Note that the data on the map is derived from anthropological observations going back more than a century; individual classifications and/or locations may be incorrect or out of date. 
Dekker, 'Him makeum walk straight': using simulation to explore Australian Aboriginal skin groups

The 8-skin system was derived from an older 4-skin or "section" system, still widely used across Australia (Figure 3). The system of the Alyawarr people (Figure 2) is one example. Linguistic analysis shows that these "sections" were not subdivided to give 8 "subsections." Instead, there was a weaving together of 4-skin (section) systems from people speaking different languages. That is to say, the designers of the 8-skin system (a) discovered the mathematical structure which is now called $\mathrm{D}_{4}$, and (b) redesigned their society on the basis of that structure, weaving together two 4-skin systems.

The 4-skin or "section" system was in turn derived from yet older systems in which people were divided into two groups (let us say, A and B). These older systems include 2-skin or moiety systems where group A must marry group B, and the children inherit the group of their father (patrimoiety) or mother (matrimoiety). They also include "generational moiety" systems where there is a somewhat different binary classification. Both the 4-skin and 8-skin systems were spreading through Australian Aboriginal society up until the $20^{\text {th }}$ century.

The various skin group systems restrict sexual relations to designated partner skin groups, and these restrictions are reinforced by traditional stories and strong taboos. For example, the stories about the Seven Sisters (Pleiades) from the western part of Australia tell how seven sisters flee across the land, and ultimately into the sky, because they are pursued by a man who is outside their designated partner skin group (Neale, 2017). Up until recent times, these taboos were reinforced by strict penalties (Smith, 2004). The introduction of the 8-skin "subsection" system appears to have facilitated marriage to other tribes without breaking taboos.

The Australian anthropologist Francis James Gillen recorded a conversation from the 1890s with an Arrernte elder who justified a switch from the 4-skin to the 8-skin system with the words (in the Australian Kriol language) "That one very good him makeum walk straight" (Koch, 2018). This statement is very significant, and provides some clues as to what the original designers might have been thinking. The words "that one very good" might include an admiration for the mathematical elegance of the system, but the words "him makeum walk straight" indicate a perception of clear functional benefits to Aboriginal society. In this paper we will use simulation to explore what those benefits might have been.

Robert Heinlein, in his young adult science fiction novel Citizen of the Galaxy (Heinlein, 1957), points out that moiety (2-skin) systems would be beneficial for spacefaring people travelling the galaxy in starships. He also notes the way that such systems encourage exogamy (marriage outside the group): "[...] One of those girls is your future wife... unless you find a bride on another ship."

\section{MATHEMATICAL STRUCTURE AND ALTERNATIVES}

Within the 8-skin system based on $\mathrm{D}_{4}$, we have $\phi^{2}=i$ (where $i$ is the identity function). That is, paternal descent follows a 2-cycle (one's skin group is the same as one's paternal grandfather). We also have $\mu^{4}=i$ (maternal descent follows a 4-cycle).

A woman's marriage partner can be found in Figure 1 by following a dashed red arrow ( $\mu$ ) to her child, and then an inverse solid blue arrow $\left(\phi^{-1}=\phi\right)$ to the child's father. For example, a Ngari-Boolūngi (rainbird) woman has Gūmerūngi (rock) children, who must have a Burulūngi (lightning) father.

Conversely, a man's marriage partner can be found by following a solid blue arrow $(\phi)$ to his child, and then an inverse dashed red arrow $\left(\mu^{-1}\right)$ to the child's mother. For example, a Ngari-Boolūngi (rainbird) man has Būngaringi (brown hawk) children, who must have a Burulūngi (lightning) mother.

We use the term spousal symmetry for the fact that this relationship works both ways (i.e. Ngari-Boolūngi and Burulūngi always marry each other). In symbols, $\phi^{-1} \mu=\mu^{-1} \phi$, so that $\phi^{-1} \mu \phi^{-1}=\mu^{-1}$. Together with $\phi^{2}=i$ and $\mu^{4}=i$, this uniquely identifies the dihedral group $D_{4}$, which is the group of symmetries of the square (Humphreys, 1996). For this reason, we can visualise the skin groups as a square, such as the one in Figure 4, with the dashed red arrows $(\mu)$ corresponding to rotations, and the solid blue arrows $(\phi)$ corresponding to flipping the square over.

We also have the property that all four of someone's grandparents have distinct skin groups (we abbreviate this as distinct grandparents), since $\phi^{-2}=i, \phi^{-1} \mu^{-1}=\phi \mu^{3}, \mu^{-1} \phi^{-1}=\phi \mu$, and $\mu^{-2}=\mu^{2}$ are always different.

One of the important properties of the diagrams in Figure 1 and Figure 4 is that they should be vertextransitive networks, i.e. that the rules should be symmetrical with respect to skin groups. If this were not so, the resulting asymmetry would cause too many, or not enough, people to be born into certain skin groups. Vertex-transitive networks with fewer than 10 nodes are always Cayley graphs of groups, so all the alternative structures with 8 skin groups must be Cayley graphs constructed using two generators (corresponding to the blue arrows $\phi$ and the red arrows $\mu$ ). This rules out the group $Z_{2} \times Z_{2} \times Z_{2}$, which has three generators, leaving us only three groups as alternative structures to $\mathrm{D}_{4}$ (i.e. $\mathrm{Z}_{2} \times \mathrm{Z}_{4}, \mathrm{Z}_{8}$, and $\mathrm{Q}_{8}$ ). 


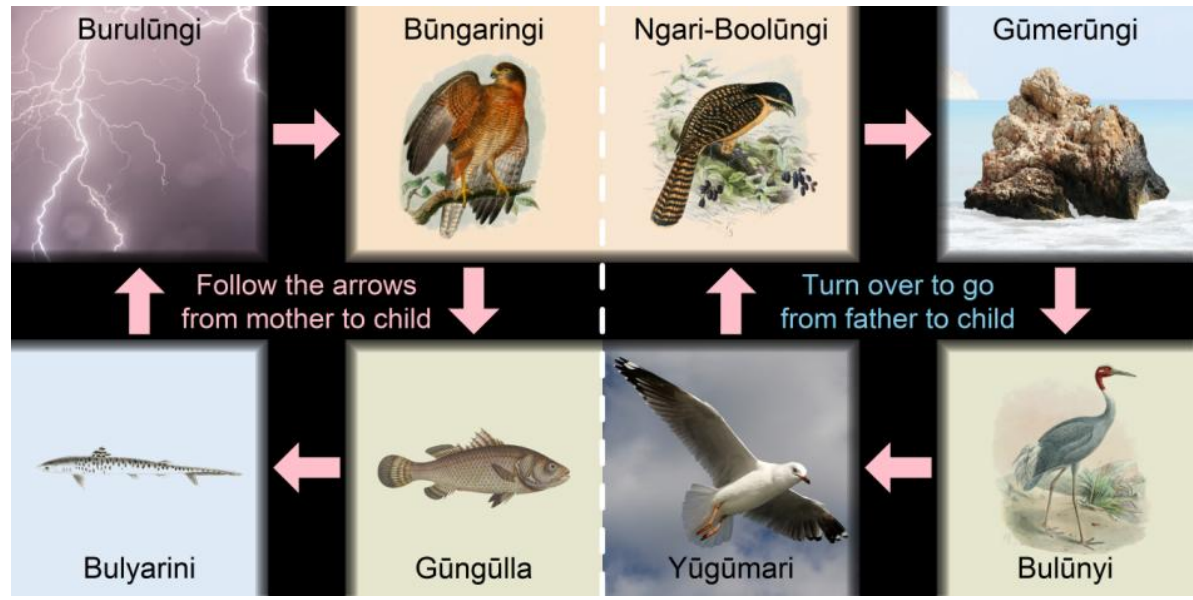

Figure 4. Cutting out this image and folding on the dotted line gives an alternative picture of Lardil skin groups (from Dekker, 2019). Pink arrows correspond to the red arrows in Figure 1, and flipping the square over corresponds to the blue arrows in Figure 1 (i.e. Burulūngi and Gūmerūngi map to each other, etc.).

We further assume, as in existing Aboriginal skin systems, that the blue $(\phi)$ cycles are smaller than, or the same size as, the red $(\mu)$ cycles. This gives us the alternatives in Figure 5, which are as follows:

\subsection{The group $Z_{2} \times Z_{4}$}

Figure 5(a) shows the variation on Figure 1 where both red $(\mu)$ cycles run in the same direction. This is a Cayley graph of the group $Z_{2} \times Z_{4}$. This has the commutative property that $\phi \mu=\mu \phi$, and therefore it does not have spousal symmetry or the distinct grandparents property. It does, however, retain the paternal (blue) 2cycles of the $\mathrm{D}_{4}$ system $\left(\phi^{2}=i\right)$.

It should be noted that the 4-skin system in Figure 2 corresponds to the Klein four-group, which is both the dihedral group $D_{2}$ and the product group $Z_{2} \times Z_{2}$. From a mathematical point of view, the two groups $D_{4}$ and $\mathrm{Z}_{2} \times \mathrm{Z}_{4}$ are therefore both logical generalisations of the 4-skin system.

\subsection{The group $\mathbf{Z}_{8}$}

Figure 5(b) shows the variation on Figure 1 where there is a single red $(\mu)$ cycle of length 8 (i.e. $\mu^{8}=i$ ). This is a Cayley graph of the group $\mathrm{Z}_{8}$. This again has the commutative property that $\phi \mu=\mu \phi$, and therefore it does not have spousal symmetry or the distinct grandparents property. It retains paternal (blue) 2-cycles.

\section{3. $\quad Z_{8}(b)$, an alternate system from the group $Z_{8}$}

Figure 5(c) shows the variation on Figure 5(b) where there is a single red $(\mu)$ cycle of length 8 (i.e. $\left.\mu^{8}=i\right)$ and two blue $(\phi)$ cycles of length 4 (i.e. $\phi^{4}=i$ ). This is also a Cayley graph of the group $\mathrm{Z}_{8}$, with the commutative property, and therefore not spousal symmetry or the distinct grandparents property.

There is a further variation of this system in which the two blue $(\phi)$ cycles run in the opposite direction. This was also simulated, but performance was inferior to $\mathrm{Z}_{8}(\mathrm{~b})$, and so this variation was not included in the experimental results below.

\subsection{The group $Q_{8}$}

Figure 5(d) shows a system, based on the quaternion group $\mathrm{Q}_{8}$, in which both the red $(\mu)$ cycles and the blue $(\phi)$ cycles have length 4 (i.e. $\mu^{4}=\phi^{4}=i$ ). It also satisfies $\mu^{2}=\phi^{2}$ and therefore lacks the distinct grandparents property (maternal grandmothers and paternal grandfathers have the same skin group). Spousal symmetry is also not satisfied, since $\phi^{-1} \mu \phi=\mu^{-1}$.

\section{SIMULATING SKIN GROUPS}

As in Dekker (2019), we explore the function of the skin group system using a NetLogo simulation (Wilensky, 1999). We simulate bands of three different initial sizes, with a fertility rates such that the population grows and then oscillates around means of 80,230, and 590. These bands are assumed to form part of a larger people-group; if members of the band cannot find skin-appropriate partners within the band, they find them outside (young women were also allowed to partner skin-appropriate men from the same generation or the previous two generations). 

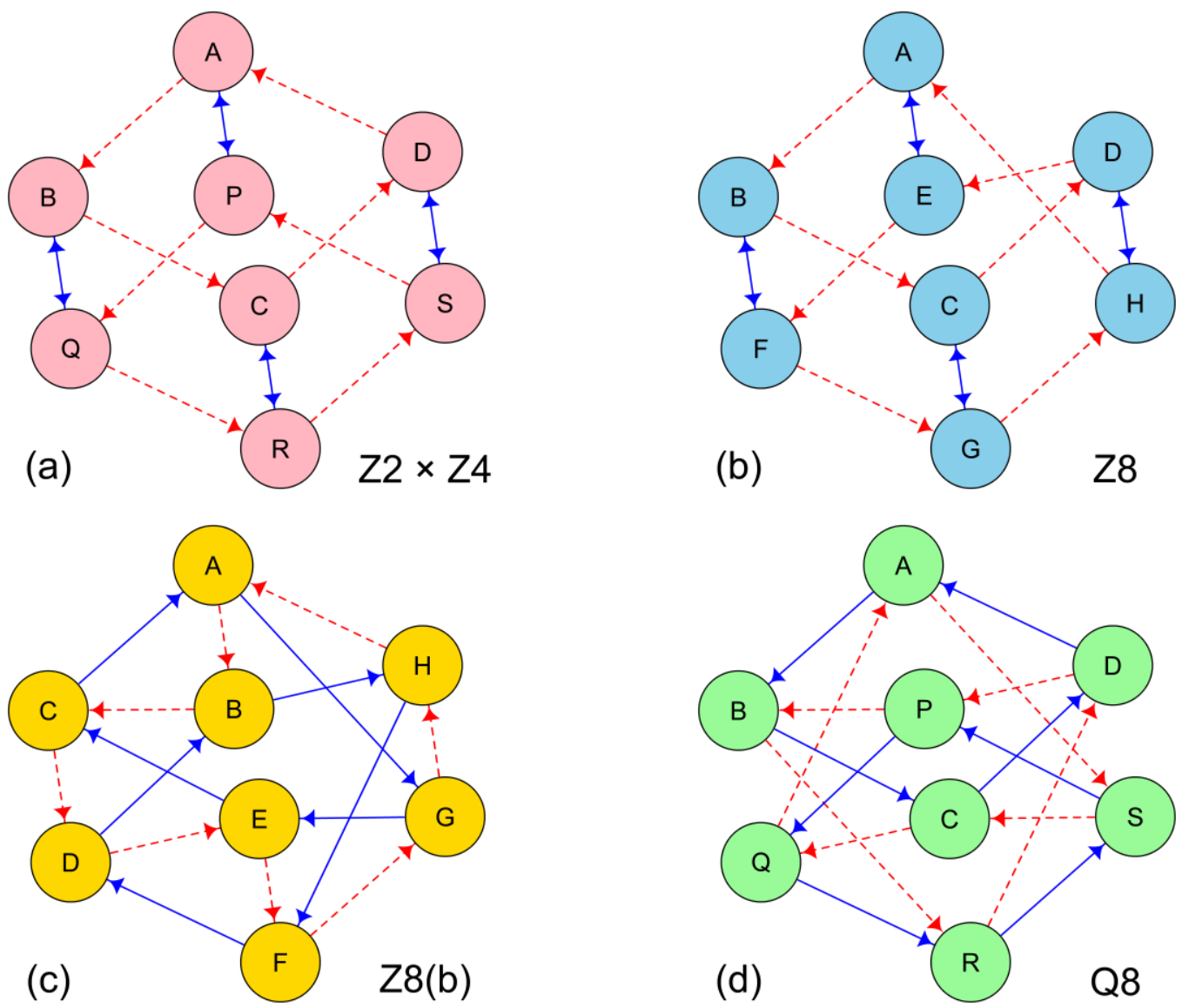

Figure 5. Four alternative mathematical structures for systems of 8 skin groups

It was rare for Aboriginal women to be unmarried (Berndt and Berndt, 1985), but in the simulation this seeking of outside partners was assumed to be not always successful (a success rate of $75 \%$ for exogamy was assumed). The simulation runs for 300 generations (i.e. around 6,000 years).

Each simulated person in the model has 68,000 genetic base pairs where mutations can lead to recessive lethal disorders, and an average of 0.29 such mutations per haploid set, as in Gao et al. (2015). The relevant genome was represented as a list of numerical indices of mutated loci. A mutation rate of 1 per 200 births kept the genetic load roughly constant.

We compared the five 8-skin structures, the 4-skin structure in Figure 2, a 2-skin (patrimoiety) structure, and two basic incest taboos: a loose one forbidding only marrying siblings ("no siblings") and a stricter one also forbidding marrying first cousins ("no cousins"). We ran each of variations 100 times for the large populations, 400 times for the medium-sized populations, and 1,000 times for the small populations.

Skin groups play an important part in the transmission of traditional stories, which encode knowledge vital to the tribe's long-term survival, such as the location of waterholes (Neale, 2017). Australia's climate can be unpredictable - e.g. the onset of the Darwin wet season varies by two months (Evans et al., 2014). Aboriginal people were primarily hunter-gatherers (Keen, 2021), and stories also encoded information about the optimal timing of journeys and hunter-gathering activities. For some stories, the men, or for other stories, the women, of two or more skin groups will be custodians. We simulated only stories passed along blue $(\phi)$ cycles of from father to son, or from paternal aunt to niece. Whenever all the living members of a blue cycle died, their stories were assumed to die with them. Partners brought in from outside were assumed not to bring in stories.

\section{RESULTS}

The means of the number of deaths due to recessive lethal genes are shown in Figure 6. The error bars show 95\% confidence intervals of the mean obtained by bootstrapping. The 8-skin systems all perform significantly better than the 2-skin (patrimoiety) or 4-skin (as in Figure 2) systems. 


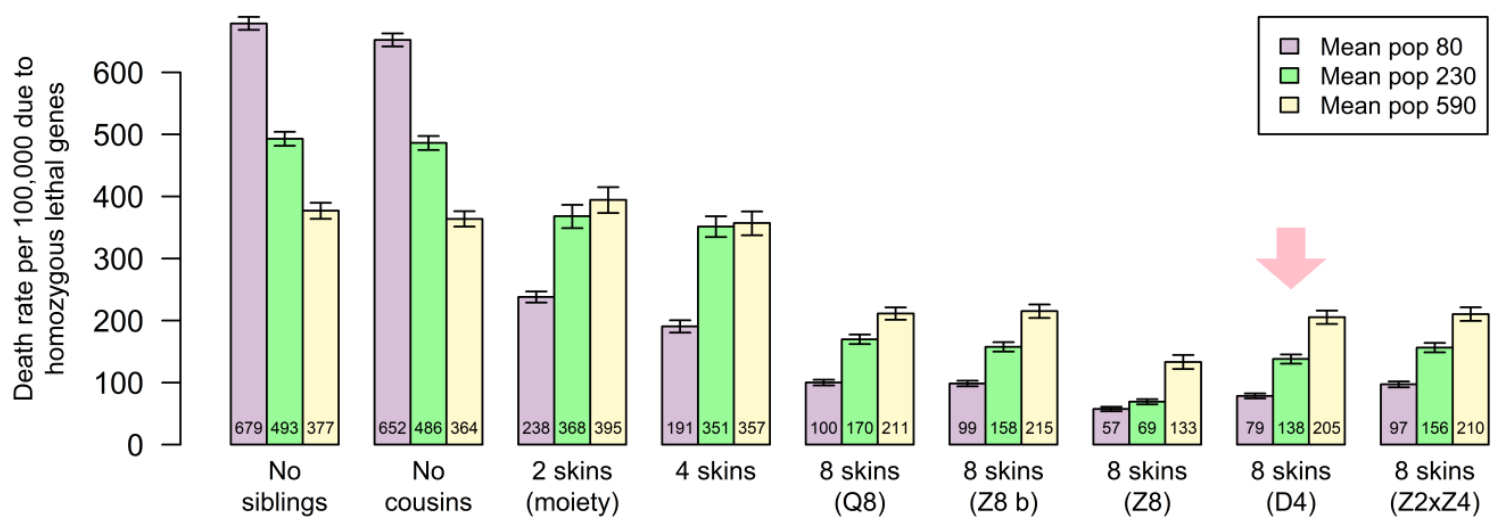

Figure 6. Simulated deaths due to recessive lethal genes. The arrow marks the Aboriginal $\mathrm{D}_{4}$ system.

The skin-based systems operated by encouraging exogamy, as Figure 7 shows. This explains why they have a stronger effect in smaller populations. In contrast, for simple incest taboos, inbreeding is least when the population is large. The best-performing system is $Z_{8}$. This is because the single red $(\mu)$ cycle of length 8 causes multiple skin groups to vanish, thereby forcing a high degree of exogamy (which might be infeasible).

Figure 8 shows the simulated retention of stories. The $\mathrm{D}_{4}$ system actually used by Aboriginals performed better than $\mathrm{Z}_{8}$ for medium-sized populations $(p=0.0000013$ by t-test $)$ and better than $\mathrm{Z}_{2} \times \mathrm{Z}_{4}$ for small populations ( $p=0.00009$ by t-test). The two systems with blue 4-cycles performed substantially worse than the 4-skin system in Figure 2 for small populations $\left(p<10^{-15}\right)$. The $\mathrm{D}_{4}$ system therefore does seem to be the best option for transmitting stories.

\section{DISCUSSION}

Table 1 summarises the properties of the various structures that might have been used instead of $\mathrm{D}_{4}$. If "him makeum walk straight" includes abstract mathematical properties such as distinct grandparents and spousal symmetry, then $\mathrm{D}_{4}$ was already preferred over the other potential alternatives. Figure 8 shows that $\mathrm{D}_{4}$ is also best at preserving stories, and Figure 6 shows that it is genetically equal to or better than all the option except $\mathrm{Z}_{8}$. The long-ago designers of the 8-skin ("subsection") system therefore did indeed make the best choice in extending the older 4-skin ("section") structure.

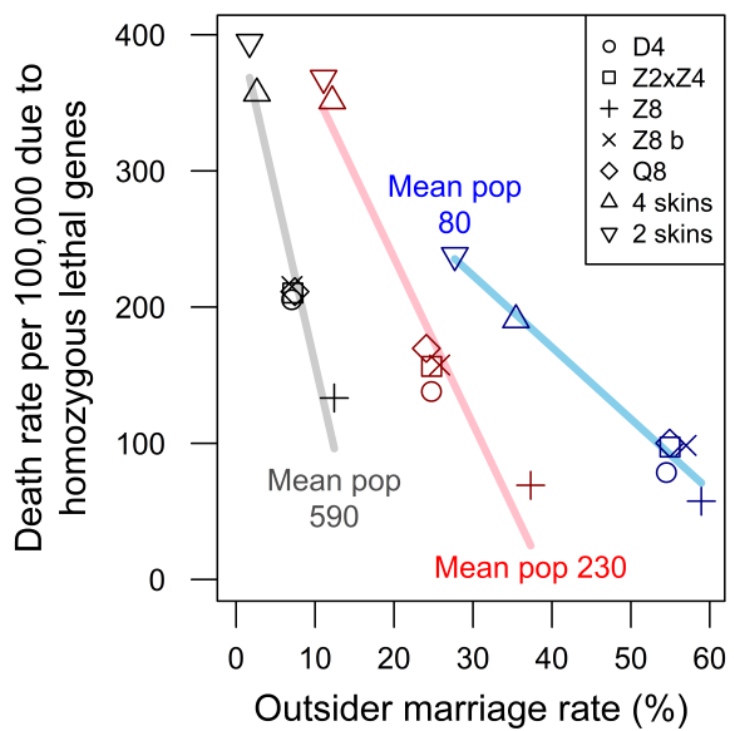

(a) Mean results for each combination of structure and population. Each regression is highly significant, with $p<10^{-15}$. The three correlations range from 0.96 to 0.98 .

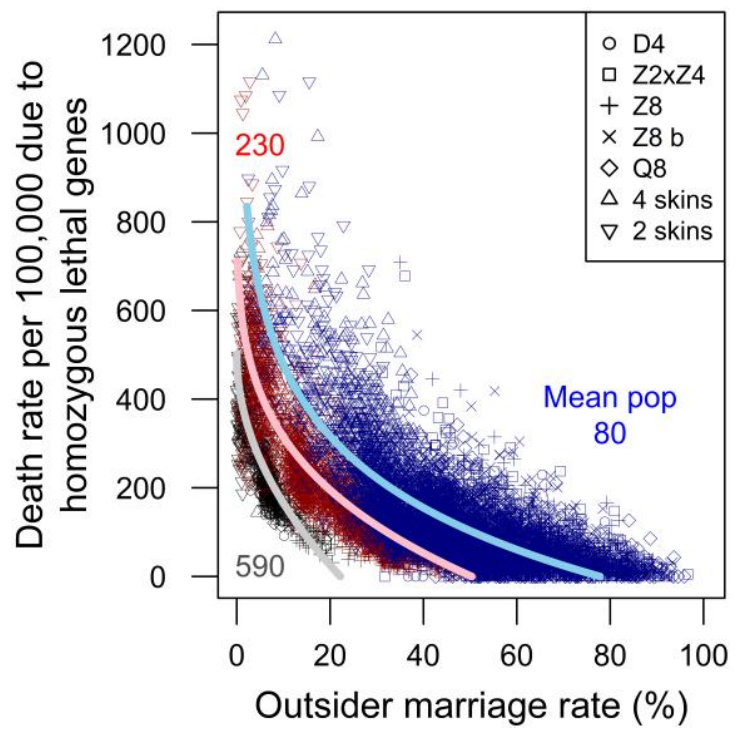

(b) Results for each experimental run. The three curves are square root, $4^{\text {th }}$ root, and logarithmic. In each case, $p<0.00002$, and the correlations range from 0.78 to 0.88 .

Figure 7. For skin-based systems, the death rate due to recessive lethal genes depends on the population size and the rate of exogamy. 


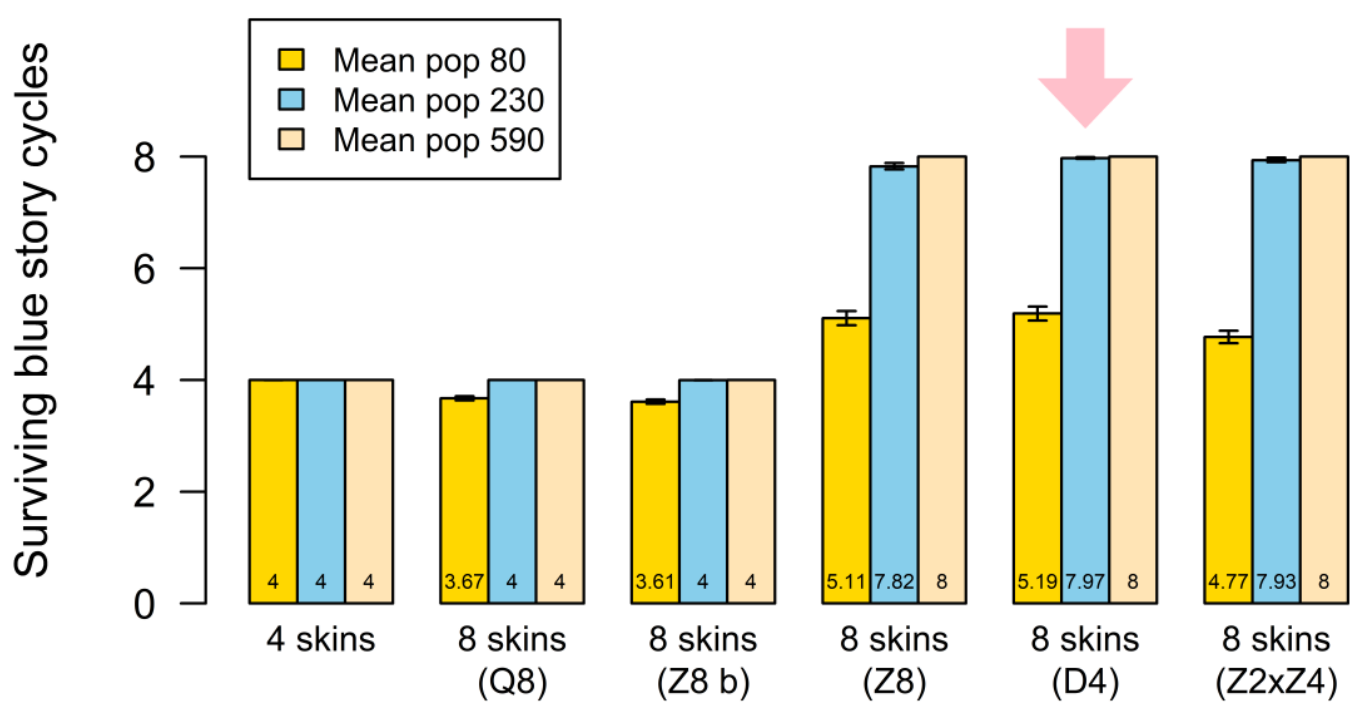

Figure 8. Simulated retention of stories passed along blue $(\phi)$ cycles. For systems with blue 4-cycles, the maximum number of stories is half that of other systems (or else people have to remember twice as many stories). The arrow marks the Aboriginal $\mathrm{D}_{4}$ system. Error bars show $95 \%$ confidence intervals of the mean.

\section{REFERENCES}

AustKin, 2021. The AustKin project, viewed March 2021, www.austkin.net.

Berndt, R.M., Berndt, C.H., 1985. The World of the First Australians. Rigby, Adelaide.

Binnion, J., 1987. The Lardil people of Mornington Island (student handbook and teacher handbook). Aboriginal Community College, Port Adelaide.

Dekker, A.H., 2019. Skin groups and Onan: computer simulation as an aid to understanding anthropological phenomena. In Elsawah, S. (ed.) MODSIM2019, $23^{\text {rd }}$ International Congress on Modelling and Simulation. Modelling and Simulation Society of Australia and New Zealand, December 2019, 842-848. ISBN: 978-0-9758400-9-2. https://doi.org/10.36334/modsim.2019.J1.dekker

Dousset, L., 2018. Systems in Geography or Geography of Systems? Attempts to Represent Spatial Distributions of Australian Social Organisation. In McConvell et al. (2018), 43-83.

Evans, S., Marchand, R., Ackerman, T., 2014. Variability of the Australian Monsoon and Precipitation Trends at Darwin, Journal of Climate 27(22), 8487-8500.

Gao, Z., Waggoner, D., Stephens, M. Ober, C., Przeworski, M., 2015. An estimate of the average number of recessive lethal mutations carried by humans. Genetics 199(4), 1243-1254.

Heinlein, R.A., 1957. Citizen of the Galaxy. Scribner.

Humphries, J., 1996. A Course in Group Theory. Oxford University Press, Oxford.

Keen, I., 2021. Foragers or Farmers: Dark Еmu and the Controversy over Aboriginal Agriculture. Anthropological Forum, 5 January, www.tandfonline.com/doi/full/10.1080/00664677.2020.1861538

Koch, H., 2018. The Development of Arandic Subsection Names in Time and Space. In McConvell et al. (2018), 317-359.

McConvell, P., Kelly, P., Lacrampe, S., eds., 2018. Skin, Kin and Clan: The Dynamics of Social Categories in Indigenous Australia. ANU Press, apo.org.au/sites/default/files/resource-files/2018-04/aponid139761.pdf

McConvell, P., 2018a. Revisiting Aboriginal social organisation. Introduction to McConvell et al. (2018), pp. $1-20$.

McConvell, P., 2018b. The Birds and the Bees: The Origins of Sections in Queensland. In McConvell et al. (2018), 219-270.

McKnight, D., 1999. People, Countries, and the Rainbow Serpent: Systems of classification among the Lardil of Mornington Island. Oxford University Press.

Neale, M., ed., 2017. Songlines: tracking the Seven Sisters. National Museum of Australia.

Smith, C., 2004. Country, Kin and Culture: Survival of an Australian Aboriginal Community. Wakefield Press, Adelaide.

White, D.R., Denham, W.W., 2007. The Indigenous Australian marriage paradox. Third General Scholarly Meeting of the Society for Anthropological Sciences (SASci). San Antonio, Texas, Feb. 21-24.

Wilensky, U., 1999. NetLogo: ccl.northwestern.edu/netlogo. Center for Connected Learning and ComputerBased Modeling, Northwestern University, Evanston, IL. 